\title{
High-Fat Diet-Induced Obesity Ablates Gastric Vagal Afferent Circadian Rhythms
}

\author{
Stephen J. Kentish, ${ }^{1,3}$ Andrew D. Vincent, ${ }^{1,2,3}$ David J. Kennaway, ${ }^{4}$ Gary A. Wittert ${ }^{1,2,3}$ and Amanda J. Page ${ }^{1,3,5}$ \\ ${ }^{1}$ Discipline of Medicine and ${ }^{2}$ Freemasons Foundation Centre for Men's Health, The University of Adelaide, Adelaide, South Australia 5005, Australia, \\ ${ }^{3}$ South Australian Health and Medical Research Institute, North Terrace, Adelaide, South Australia 5000, Australia, ${ }^{4}$ Robinson Research Institute, \\ Discipline of Obstetrics and Gynaecology, University of Adelaide, Adelaide, South Australia 5006, Australia, and ${ }^{5}$ Royal Adelaide Hospital, North Terrace, \\ Adelaide, South Australia 5000, Australia
}

Rats with high-fat diet (HFD)-induced obesity increase daytime eating, suggesting an alteration in circadian food intake mechanisms. Gastric vagal afferents (GVAs) respond to mechanical stimuli to initiate satiety. These signals are dampened in HFD mice and exhibit circadian variations inversely with food intake in lean mice. Furthermore, leptin shows circadian variation in its circulating level and is able to modulate GVA mechanosensitivity. However, whether leptin's ability to modulate GVAs occurs in a circadian manner is unknown. Therefore, we investigated whether changes in the circadian intake of food in HFD-induced obesity is associated with a disruption in GVA circadian rhythms. Eight-week-old male C57BL/6 mice were fed a standard laboratory diet (SLD) or a HFD for 12 weeks. A subgroup of SLD and HFD mice were housed in metabolic cages. After 12 weeks, ex vivo GVA recordings were taken at $3 \mathrm{~h}$ intervals starting at zeitgeber time 0 (ZT0) and stomach content was measured. After 12 weeks, HFD mice consumed more food during the light phase through larger and more frequent meals compared with SLD mice. SLD mice exhibited circadian fluctuation in stomach content, which peaked at ZT18 and reached a nadir at ZT9. At these time points, both tension and mucosal receptor mechanosensitivity were the lowest and highest, respectively. HFD mice exhibited little circadian variation in stomach content or GVA mechanosensitivity. Leptin potentiated mucosal receptor mechanosensitivity only in SLD mice and with reduced potency during the dark phase. In conclusion, loss of circadian variation in GVA signaling may underpin changes in eating behavior in HFD-induced obesity.

Key words: circadian; food intake; leptin; obesity; stomach; vagus

\section{Significance Statement}

Appropriate circadian control of food intake is vital for maintaining metabolic health. Diet-induced obesity is associated with strong circadian changes in food intake, but the contributing mechanisms have yet to be determined. Vagal afferents are involved in regulation of feeding behavior, particularly meal size, and have been shown to exhibit circadian fluctuation in mechanosensitivity, potentially allowing for time of day-specific levels of satiety signaling. Our study indicates that, in diet-induced obesity, these circadian fluctuations in gastric vagal afferent mechanosensitivity are lost. This was accompanied by increased light phase eating, particularly increased meal size. This is the first evidence that diet-induced disruption to vagal afferent signaling may cause a perturbation in circadian eating patterns.

\section{Introduction}

Food intake exhibits strong circadian rhythmicity. In rodents, up to $80 \%$ of total food intake occurs at night (Denis et al., 2003).

Received July 16, 2015; revised Jan. 27, 2016; accepted Jan. 31, 2016.

Author contributions: S.J.K., D.J.K., G.A.W., and A.J.P. designed research; S.J.K. and A.J.P. performed research; S.J.K. and A.D.V. analyzed data; S.J.K., A.D.V., D.J.K., G.A.W., and A.J.P. wrote the paper.

This work was supported by the National Health and Medical Research Council (NHMRC Project Grant 1046289). S.J.K. is funded by an NHMRC Peter Doherty Fellowship (1091586).

The authors declare no competing financial interests.

Correspondence should be addressed to either Stephen Kentish or Amanda Page, Centre for Nutrition and Gastrointestinal Diseases, Discipline of Medicine, Level 7 SAHMRI, North Terrace, Adelaide, SA 5000, Australia, E-mail: stephen.kentish@adelaide.edu.au or amanda.page@adelaide.edu.au.
This coincides with the time period in which physical activity is highest (Pendergast et al., 2013). Circadian behaviors are largely maintained through the presence of a light-entrained clock located in the suprachiasmatic nucleus (SCN) (Gillette and Tischkau, 1999), which in turn entrains peripheral clocks (Schibler et al., 2003). We have shown previously that there is circadian expression of clock genes in the nodose ganglia, where the cell bodies for vagal afferents lie (Kentish et al., 2013).

Gastric vagal afferents (GVAs) are part of a coordinated set of mechanisms modulating meal size (Cummings and Overduin, 
2007). There are two classes of GVA identified in the mouse stomach (Kentish et al., 2012). Tension receptors signal stretch induced by the consumption of food, resulting in feelings of satiety (Wang et al., 2008). Mucosal receptors respond to fine tactile stimuli brushing up against the mucosa (Kentish et al., 2012) and are believed to be involved in regulating gastric motor function to delay gastric emptying until food has been suitably digested (Becker and Kelly, 1983). Both gastric tension and mucosal receptors exhibit circadian variations in their response to mechanical stimuli, with peak levels of mechanosensitivity occurring during the light phase (LP) and low levels during the dark phase (DP) (Kentish et al., 2013), which may allow for time of day-specific regulation of food intake.

Rats with high-fat diet (HFD)-induced obesity consume more food during the LP through increased meal size (Furnes et al., 2009). The mechanism responsible for this has not been established. Seven days of HFD feeding has been shown to induce a $5 \mathrm{~h}$ advance in the hepatic, but not the SCN, clock (Pendergast et al., 2013), suggesting that diet may modulate peripheral clocks directly. We have shown previously that, in response to HFD-induced obesity, the mechanosensitivity of GVA tension receptors is reduced (Kentish et al., 2012), the effect of leptin switches from potentiating mucosal receptors to inhibiting tension receptors, and the effect of ghrelin switches from inhibiting only tension receptors to inhibiting both tension and mucosal receptors (Kentish et al., 2012, 2014). Because GVAs regulate meal size, we sought to determine the effect of HFDinduced obesity on patterns of food intake and the relationship of these to circadian variations of GVA mechanosensitivity and clock gene expression in the nodose ganglia.

\section{Materials and Methods}

Ethics. All studies were approved and performed in accordance with the guidelines of the Animal Ethics Committees of the University of Adelaide and SA Pathology, Adelaide, Australia.

Mice. Male C57BL/6 mice, 7 weeks of age, were acclimatized for 1 week before being randomly assigned to a standard laboratory diet (SLD; $12 \%$ energy from fat) or HFD (60\% energy from fat) group ( $n=60 /$ diet $)$ for 12 weeks. Mice were housed with littermates in groups of four for the duration of the study. Weights were monitored weekly. All mice were housed under a 12:12 h light/dark cycle, with lights on at $0600 \mathrm{~h}$ [Zeitgeber time 0 (ZT0)]. All mice had ad libitum access to food and water up until the time of the experiments, which were undertaken every $3 \mathrm{~h}$ commencing at ZT0 ( $n=6-9$ per time point).

To elucidate whether changes observed in GVA circadian rhythms were due to the increased consumption of fat or increased weight, a separate cohort of mice were fed SLD or HFD for 2 weeks, a time point previously observed to be just before a separation in weight gain between SLD- and HFD-fed mice (Kentish et al., 2014). These animals were killed at $6 \mathrm{~h}$ intervals starting at ZT0 for in vitro electrophysiology recordings to determine mechanosensitivity of gastric vagal afferents.
C Light/dark energy expenditure
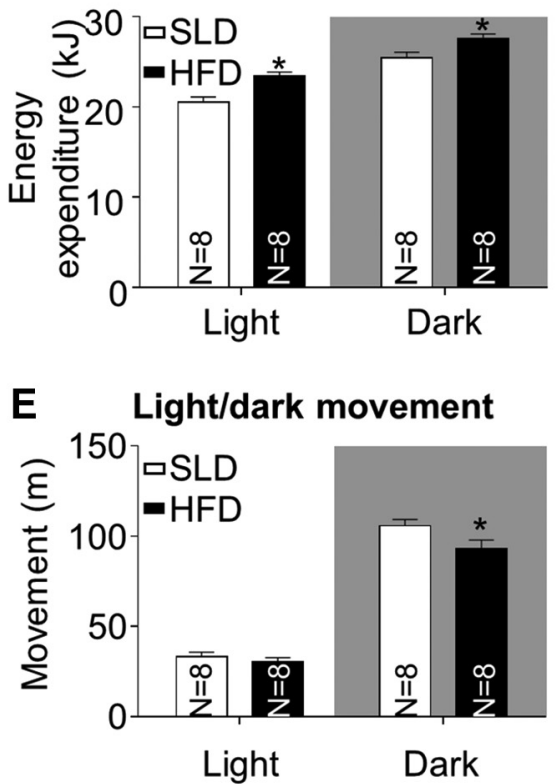

Figure 1. Mouse metabolic characteristics. $\boldsymbol{A}-\boldsymbol{C}$, Body weight gain $(\boldsymbol{A}), 24 \mathrm{~h}(\boldsymbol{B})$, and $L P$ and DP energy expenditure $(\boldsymbol{C})$ in SLD and HFD mice. $\boldsymbol{D}, \boldsymbol{E}, 24 \mathrm{~h}(\boldsymbol{D})$ and $L P$ and DP movement $(\boldsymbol{E})$ of the SLD and HFD mice. For $\boldsymbol{A}, \boldsymbol{B}$, and $\boldsymbol{D},{ }^{*} p<0.05$ versus SLD unpaired $t$ test; for $\boldsymbol{C}$ and $\boldsymbol{E},{ }^{*} p<0.05$ versus SLD two-way ANOVA, Sidak post hoc test. were individually housed in metabolic monitoring cages (Promethion; Sable Systems International) for 12 weeks to establish food intake patterns, movement, and energy expenditure throughout the circadian cycle. There were no differences in metabolic parameters at the beginning of the study between the SLD and HFD mice.

Ex vivo mouse GVA preparation. This preparation has been described in detail previously (Page et al., 2002). In short, mice were anesthetized with isoflurane and killed via exsanguination followed by decapitation. The thorax was opened by a midline incision and the stomach and esophagus were removed. After removal, with vagal nerves attached, the stomach and esophagus were opened longitudinally and pinned down mucosa side up in an organ bath containing a Krebs solution composing of the following (in mM): $118.1 \mathrm{NaCl}, 4.7 \mathrm{KCl}, 25.1 \mathrm{NaHCO}_{3}, 1.3 \mathrm{NaH}_{2} \mathrm{PO}_{4}, 1.2$ $\mathrm{MgSO}_{4} .7 \mathrm{H}_{2} \mathrm{O}, 1.5 \mathrm{CaCl}_{2}, 1.0$ citric acid, 11.1 glucose, and 0.001 nifedipine bubbled with $95 \% \mathrm{O}_{2}-5 \% \mathrm{CO}_{2}$. Gastric content was determined during the dissection process by weighing the tissue before and after the stomach was opened.

Characterization of GVA properties. The process to identify mouse GVA mechanosensitivity has been described in detail previously (Kentish et al., 2012). Briefly, mucosal receptors respond to mucosal stroking, but not to circular tension, and tension receptors respond to both mucosal stroking and tension. Receptive fields of these receptors were first located in the stomach using a brush; once located, specific stimuli were applied. Mucosal stroking was performed using a calibrated von Frey hair $(50$ $\mathrm{mg}$ ), which was stroked across the mucosa at a rate of $5 \mathrm{~mm} \mathrm{~s}^{-1}$. Tension was applied using a threaded hook attached to an underpinned point 
\begin{tabular}{l} 
A \\
क्ञ \\
0 \\
$\frac{1}{\pi}$ \\
$\stackrel{0}{0}$ \\
0 \\
0 \\
0 \\
\hline 1
\end{tabular}
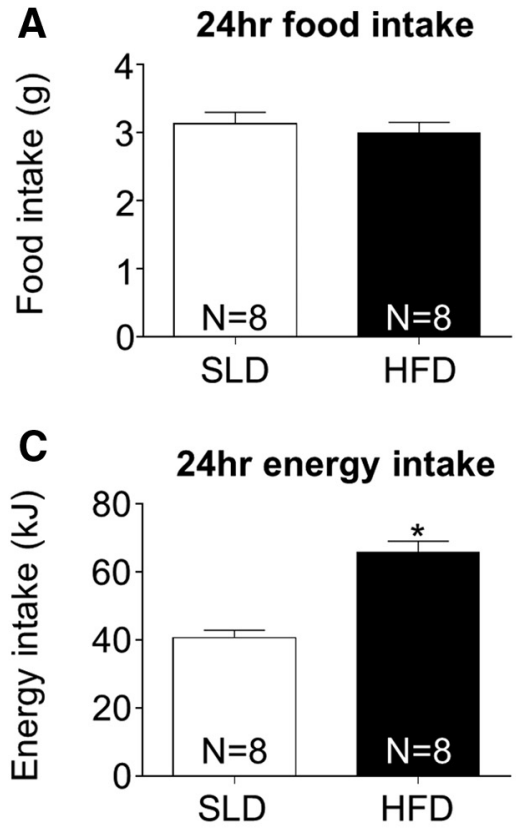

E
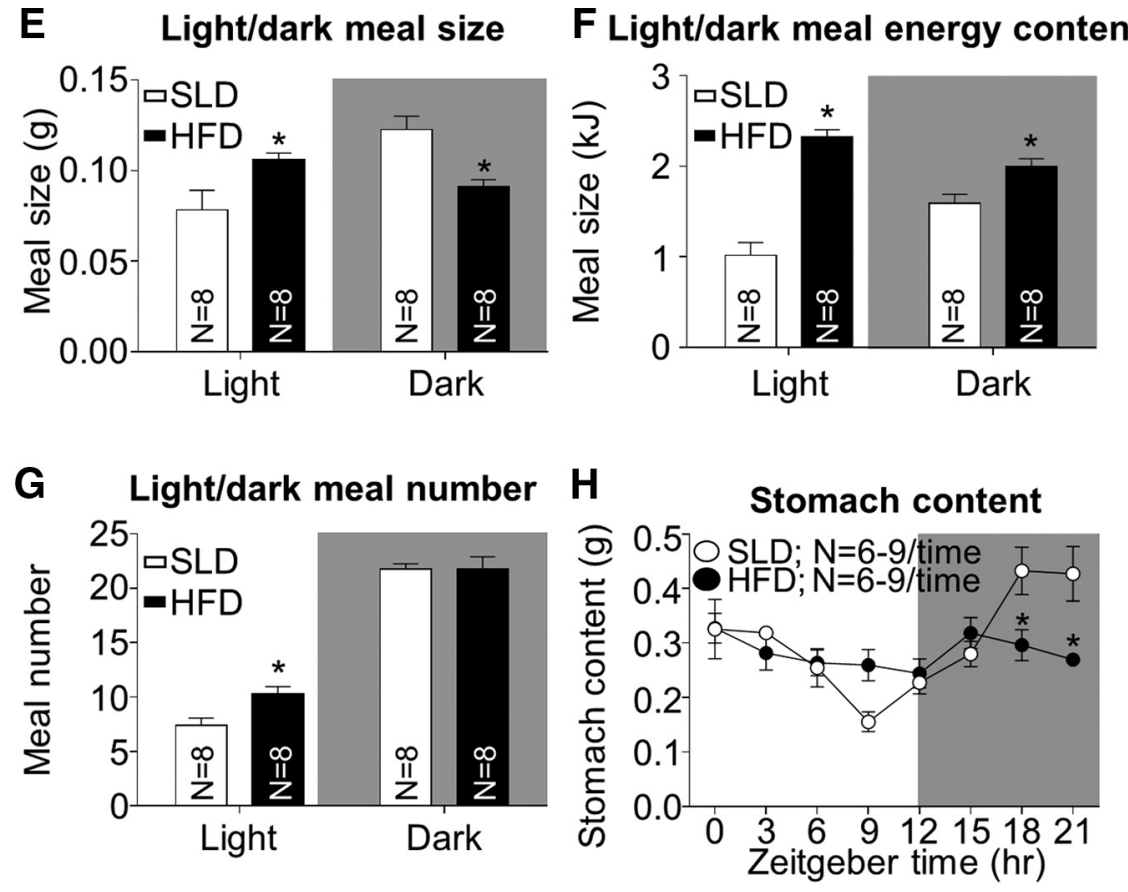

Figure 2. Food intake patterns of SLD and HFD. $\boldsymbol{A}, \boldsymbol{B}, 24 \mathrm{~h}(\boldsymbol{A})$ and $L P$ and DP food intake $(\boldsymbol{B})$ in SLD and HFD mice. $\boldsymbol{C}, \boldsymbol{D}, 24 \mathrm{~h}(\boldsymbol{C})$ and $L P$ and DP energy intake $(\boldsymbol{D})$. $\boldsymbol{E}-\boldsymbol{G}, \mathrm{LP}$ and DP meal size $(\boldsymbol{E})$, meal energy size $(\boldsymbol{F})$, and meal number $(\boldsymbol{G})$ in SLD and HFD mice. Gastric content (M) in SLD and HFD mice. For $\boldsymbol{C},{ }^{*} p<0.05$ versus SLD, unpaired $t$ test; For $\boldsymbol{B}$ and $\boldsymbol{D}-\boldsymbol{H},{ }^{*} p<0.05$ versus SLD, two-way ANOVA, Sidak post hoc test.

adjacent to the receptive field. The threaded hook was attached to a cantilever via a pulley close to the preparation. A standard weight $(3 \mathrm{~g})$ was then placed on the opposite end for $1 \mathrm{~min}$.

Effect of leptin and ghrelin on GVAs. The orexigenic peptide ghrelin and anorexigenic peptide leptin have GVA modulatory actions (Kentish et al., 2012, 2014). To determine whether these modulatory actions exhibit circadian variation, the mechanosensitivity of GVAs before and after leptin (1 nM) or ghrelin (3 nM), added to the superfusing Krebs and allowed to equilibrate for $20 \mathrm{~min}$, was determined. These concentrations are sufficient to modulate GVA mechanosensitivity (Kentish et al., 2012, 2014).
Single units were discriminated on the basis of action potential shape, duration, and amplitude by use of Spike 2 software (Cambridge Electronic Design).

$q R T-P C R$. Nodose ganglia were removed bilaterally from mice on either diet at all time points. Total RNA was extracted using a PureLink RNA Micro Kit (Life Technologies) according to the manufacturer's instructions. qRT-PCRs were performed as described in detail previously (Kentish et al., 2012). All primers used were predesigned TaqMan probes specific for circadian locomotor output cycles kaput (Clock), brain and muscle arnt like protein 1 (Bmal1), period 1 (Per1), period 2 (Per2), cryptochrome 1 (Cry1), cryptochrome 2 (Cry2), and Nuclear Receptor Subfamily 1, Group D, Member 1 (Nr1d1) (Life Technologies). Relative RNA levels were calculated using the $\Delta$ CT method (Pfaffl et al., 2002).

Statistical analysis. All data except for qRTPCR data are expressed as mean \pm SEM with $n=$ number of animals. We analyzed the data using mixed factorial ANOVAs that included the between-subjects factor of diet (SLD, HFD) and the within-subjects factor of time of day $(0$, $3,6, \ldots 24)$ or circadian photoperiod (LP, DP). Sidak post hoc tests were performed when significant main effects were present. Weight gain and $24 \mathrm{~h}$ measurements in SLD and HFD mice were analyzed using unpaired $t$ tests. The correlation between the stomach contents and GVA mechanosensitivity was analyzed by linear regression analysis. Clock gene expression between SLD and HFD mice were analyzed using a sinusoidal nonlinear mixed effects regression. Log-transformed gene relative expression was modeled, with diet, gene, and their pairwise interaction as fixed effects acting on model components: $(A)$ mean expression, $(B)$ log amplitude, and $(C)$ the shift in time. Random intercepts per individual were included per component. The period was assumed to be $24 \mathrm{~h}$. The calculations were as follows:

$$
\begin{aligned}
& y_{\mathrm{i}}=\left(A+\varepsilon_{\mathrm{A}}\right)+\exp \left(B+\varepsilon_{\mathrm{B}}\right) \\
& * \sin \left(\pi / 12\left(t-\left(C+\varepsilon_{\mathrm{C}}\right)\right)\right)+\varepsilon_{\mathrm{i}} \\
& \varepsilon_{\mathrm{i}} \sim n\left(0, \sigma^{2}\right), \varepsilon_{\mathrm{j}} \sim n\left(0, \sigma_{\mathrm{j}}^{2}\right) \text { for all } j=A-C .
\end{aligned}
$$

Quantile-quantile plots of residuals and random effect estimates were inspected visually to ensure that distributional assumptions were not violated. Analyses were performed in $\mathrm{R}$ version 3.2 using the nlme package.

\section{Results}

Diet-induced obesity

HFD mice gained more weight than the SLD mice after the 12-week period (Fig. $1 A$, SLD: $20.62 \pm 0.56 \mathrm{~g}$ HFD: $8.16 \pm 0.20 \mathrm{~g}, T_{(118)}=21.0, p<0.0001$ unpaired $t$ test). HFD mice had higher daily energy expenditure than SLD mice (Fig. $1 B$, SLD: $45.97 \pm 1.22 \mathrm{~kJ} \mathrm{HFD:} 51.00 \pm 0.91 \mathrm{~kJ}, T_{(14)}=3.3$, $p=0.0051$ unpaired $t$ test). This was due to increases in both LP (Fig. 1C, SLD: $20.53 \pm 0.56 \mathrm{~kJ}$ HFD: $23.40 \pm 0.45 \mathrm{~kJ}$,) and DP (Fig. 1C, SLD: $25.44 \pm 0.64 \mathrm{~kJ}$ HFD: $27.60 \pm 0.49 \mathrm{~kJ}$ ) expenditure. Mixed-model ANOVA analysis showed that there was a significant interaction between the diet of the mouse and photo- 

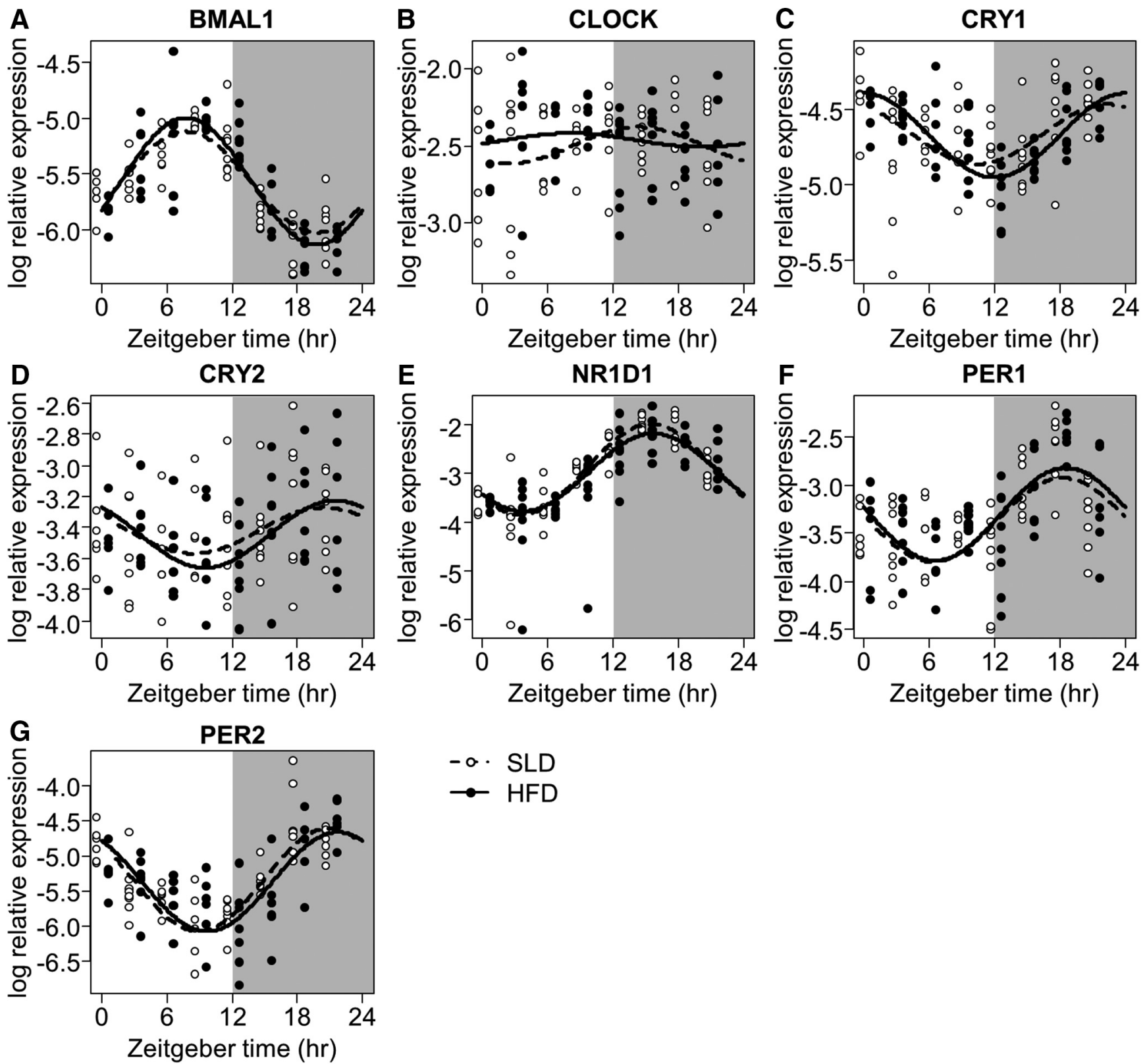

Figure 3. Expression of clock genes in nodose ganglia. Relative Bmal1 (A), Clock (B), $\operatorname{Cry} 1(\boldsymbol{C}),(r y 2(\boldsymbol{D}), \operatorname{Nr} 1 d 1(\boldsymbol{E}), \operatorname{Per} 1(\boldsymbol{F})$, and Per2 (G) mRNA content of the nodose ganglia from SLD $(\bigcirc)$ and $\operatorname{HFD}(\bullet)$ mice $(n=6-8 /$ time point) are shown. Data are individual log relative expression levels, with the lines representing the NLME model fits.

period energy expenditure $\left(F_{(1,14)}=6.1, p=0.0275\right.$, two-way ANOVA, diet $\times$ photoperiod interaction). Twenty-four-hour movement was decreased in the HFD mice $(123.90 \pm 3.68 \mathrm{~m})$ compared with the SLD mice $\left(139.30 \pm 10.83 \mathrm{~m}\right.$; Fig. $1 D, T_{(14)}=$ $2.5 p=0.0256$ unpaired $t$ test) due to no change in the LP (Fig. $1 E$, SLD: $33.49 \pm 2.37 \mathrm{~m}$; HFD: $30.59 \pm 2.22 \mathrm{~m}$ ) but a reduction in the DP (Fig. $1 E$, SLD: $105.80 \pm 3.53 \mathrm{~m}$; HFD: $93.28 \pm 4.61 \mathrm{~m}$ ). Analysis of movement differences revealed that both photope$\operatorname{riod}\left(F_{(1,14)}=360.7, p<0.0001\right.$, two-way ANOVA, photoperiod effect) and $\operatorname{diet}\left(F_{(1,14)}=6.2, p=0.0256\right.$, two-way ANOVA, effect) affected mouse movement, but there was no interaction between them $(p=0.1974$, two-way ANOVA, diet $\times$ photoperiod interaction).

Total food intake

There was no difference in the $24 \mathrm{~h}$ food intake in the HFD mice (Fig. $2 A$, SLD: $3.12 \pm 0.17$ g; HFD: $2.99 \pm 0.16$ g, $p=0.5768$ unpaired $t$ test). However, HFD mice consumed more energy in a $24 \mathrm{~h}$ period than SLD mice (Fig. $2 C$, SLD: $40.60 \pm 2.23 \mathrm{~kJ}$; HFD: $65.57 \pm 3.41 \mathrm{~kJ}, T_{(14)}=6.1, p<0.0001$ unpaired $t$ test $)$.

Food intake patterns

Relative to SLD mice, food intake during the LP was increased in the HFD mice (Fig. 2B, SLD: 0.53 $\pm .08 \mathrm{~g}$; HFD: $1.10 \pm 0.06 \mathrm{~g}$, but lower during the DP (Fig. $2 B$, SLD: $2.58 \pm 0.14$ g; HFD: $1.89 \pm$ $0.12 \mathrm{~g})$. Statistical analysis showed that there was a significant interaction between the photoperiod and the diet of the mice content $\left(F_{(1,14)}=46.5, p<0.0001\right.$, two-way ANOVA, diet $\times$ photoperiod interaction). This translated to a greater energy consumption during the LP and DP by the HFD mice compared with the SLD mice (LP: Fig. 2D, SLD: $6.95 \pm 0.14 \mathrm{~kJ}$; HFD: $24.18 \pm 0.12 \mathrm{~kJ}$; DP: Fig. $2 D$, SLD: $33.65 \pm 2.63 \mathrm{~kJ}$; HFD: $41.39 \pm 1.79 \mathrm{~kJ})$. Mixed-model ANOVA analysis showed that there was an interaction between the photoperiod and the diet 

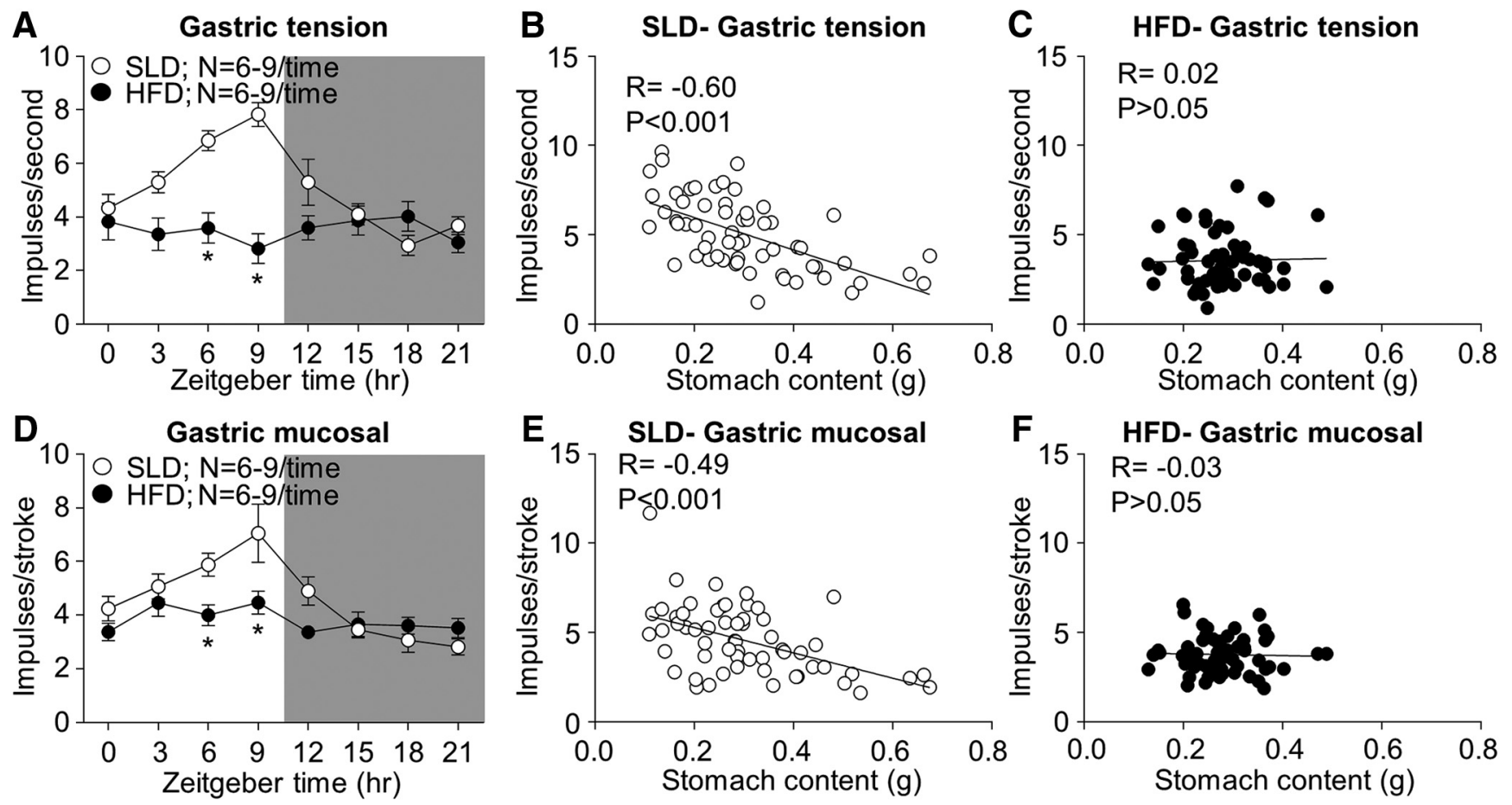

Figure 4. Circadian variation in GVA mechanosensitivity is lost in HFD mice. $A$, SLD and HFD gastric tension receptor responses to $3 \mathrm{~g}$ stretch throughout the circadian cycle. $B, C$, Correlation between SLD $(\boldsymbol{B})$ and HFD $(\boldsymbol{C}$ response to $3 \mathrm{~g}$ tension and stomach content. $\boldsymbol{D}$, SLD and HFD mucosal receptor response to mucosal stroking with a $50 \mathrm{mg}$ von Frey hair throughout the circadian cycle. $\boldsymbol{E}, \boldsymbol{F}$, Correlation between SLD $(\boldsymbol{E})$ and HFD $(\boldsymbol{F})$ responses to $50 \mathrm{mg}$ stroking and stomach content. ${ }^{*} p<0.05$ versus SLD, two-way ANOVA, Sidak post hoc test.

that the mice had been fed $\left(F_{(1,14)}=9.5, p=0.0080\right.$, two-way ANOVA, diet $\times$ photoperiod interaction).

Meal size during the LP was higher in the HFD $(0.11 \pm 0.00 \mathrm{~g})$ than the SLD mice $(0.07 \pm 0.01 \mathrm{~g})$ (Fig. $2 E)$. During the DP, HFD meal size $(0.09 \pm 0.00 \mathrm{~g})$ was lower than SLD meal size $(0.12 \pm$ $0.01 \mathrm{~g}$; Fig. 2E). Analysis of these differences using a mixed-model ANOVA revealed a significant interaction between effect caused by the diet and the photoperiod $\left(F_{(1,14)}=20.8, p=0.0004\right.$, two-way ANOVA, diet $\times$ photoperiod interaction). When meal size was expressed as the meal energy content, HFD mice consumed more energy per meal during both the LP and DP (LP: Fig. 2F, SLD: $1.02 \pm 0.14$ kJ; HFD: $2.33 \pm 0.08$ kJ, DP: Fig. $2 F$, SLD: $1.59 \pm 0.10 \mathrm{~kJ}$; HFD: $2.00 \pm 0.08 \mathrm{~kJ}$ ). Running a mixed-model ANOVA showed the presence of a significant interaction between the mouse diet and the photoperiod $\left(F_{(1,14)}=24.6, p=0.0002\right.$, two-way ANOVA, diet $\times$ photoperiod interaction).

The number of meals consumed during the light phase was higher in the HFD mice: $(10.32 \pm 0.64)$ than the SLD mice (SLD: $7.37 \pm 0.69$ ) (Fig. $2 G$ ). There was no difference in the number of meals consumed during the DP between the HFD $(21.80 \pm 1.10)$ and SLD $(21.75 \pm 0.51)$ mice (Fig. $2 G)$. Analysis of the meal number in the different photoperiods by the two different groups of mice showed the presence of a significant interaction $\left(F_{(1,14)}=4.7, p=0.0476\right.$, two-way ANOVA, diet $\times$ photoperiod interaction).

Stomach content in the SLD mice exhibited a strong circadian variation, as was observed previously (Kentish et al., 2013), with a peak content of $0.43 \pm 0.04 \mathrm{~g}$ at ZT18 and a nadir of $0.16 \pm 0.02 \mathrm{~g}$ at ZT9 (Fig. $2 H$ ). In the HFD group, the amount of food present in the stomach did not vary across the circadian cycle (Fig. $2 H$ ). Mixed-model ANOVA analysis indicated an interaction between the diet that the mice were fed and circadian pattern in gastric content $\left(F_{(7,104)}=3.2, p=\right.$ 0.0038 , two-way ANOVA, diet $\times$ time of day interaction).

\section{Clock gene expression}

All clock genes studied were detected throughout the circadian cycle (Fig. 3). There was no statistically significant difference in the magnitude of oscillation or the timing of the acrophase and trough levels of any of the clock genes studied (Bmall 2A, Clock 2B, Cry1 2C, Cry2 2D, Nrld1 2E, Per1 2F, Per2 2F).

\section{Circadian oscillations in gastric vagal afferent} mechanosensitivity

In SLD mice, there was circadian variation in the response of gastric tension receptors. An acrophase occurred at ZT9 of $7.83 \pm 0.44 \mathrm{imp} / \mathrm{s}$ in response to $3 \mathrm{~g}$ stretch. The response to $3 \mathrm{~g}$ stretch was reduced by $32 \%$ at ZT12 $(5.92 \pm 0.85 \mathrm{imp} / \mathrm{s})$, $47 \%$ at ZT15 ( $4.10 \pm 0.40 \mathrm{imp} / \mathrm{s}), 60 \%$ at ZT18 (3.06 \pm 0.28 $\mathrm{imp} / \mathrm{s}), 50 \%$ at ZT21 (3.86 $\pm 0.43 \mathrm{imp} / \mathrm{s})$, and $44 \%$ at ZT0 $(4.32 \pm 0.51 \mathrm{imp} / \mathrm{s})$ relative to the response at ZT9 (Fig. $4 A$ ). There was an inverse linear relationship between the response to tension and mass of stomach content (Fig. $4 B, r=-0.60$, $p<0.0001$ ). In HFD mice, there was minimal variation in response of gastric tension receptors throughout a circadian cycle (Fig. $4 A$ ) and no relationship between the gastric content and tension receptor mechanosensitivity (Fig. $4 C ; r=0.02$, $p=0.4227$ ). A two-way ANOVA revealed a significant interaction between the circadian oscillation of gastric tension receptor mechanosensitivity between the two diet groups $\left(F_{(7,104)}=5.5, p<0.0001\right.$, two-way ANOVA, diet $\times$ time of day interaction).

The response of gastric mucosal receptors to stroking with a $50 \mathrm{mg}$ von Frey hair exhibited circadian variation in SLD mice (Fig. 4D). The acrophase response of $7.05 \pm 1.08 \mathrm{imp} /$ stroke occurred at ZT9. This was reduced by at 50\% ZT15 (3.46 \pm 0.30 $\mathrm{imp} / \mathrm{stroke}), 56 \%$ at ZT18 (3.07 $\pm 0.46 \mathrm{imp} /$ stroke), $60 \% \mathrm{ZT} 21$ $(2.82 \pm 0.30 \mathrm{imp} /$ stroke $)$, and $39 \%$ at ZT0 (4.25 $\pm 0.46 \mathrm{imp} /$ stroke). There was a negative linear correlation between the re- 
A

Leptin 1nM-Gastric tension

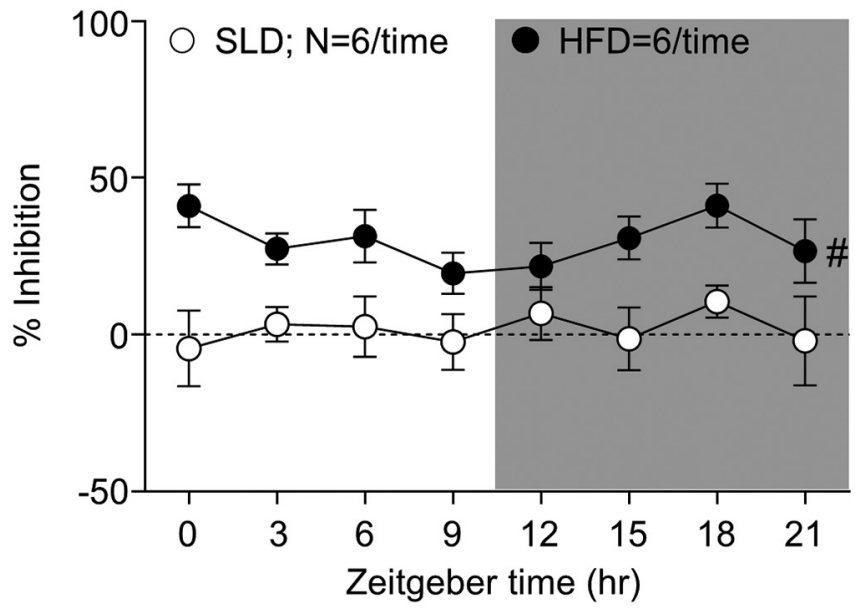

C

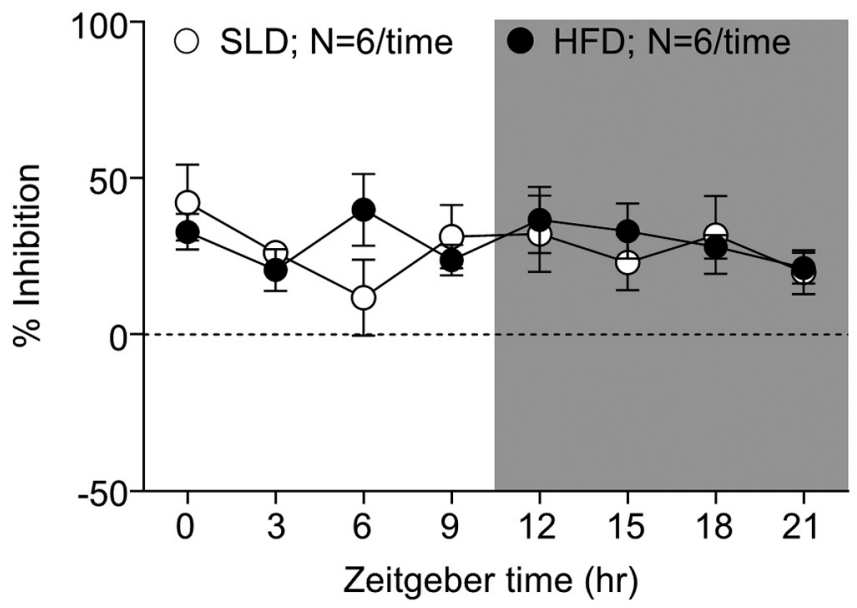

B Leptin 1nM- Gastric mucosal

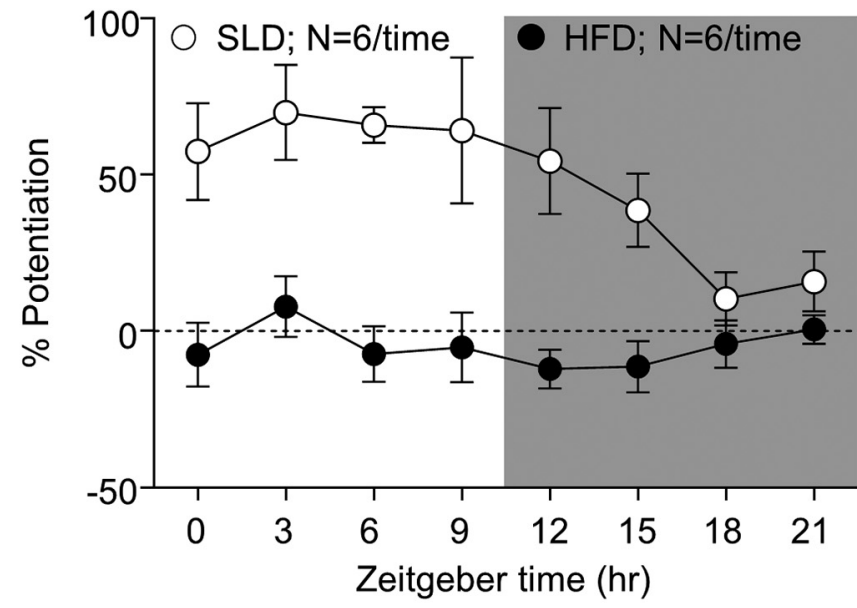

Ghrelin 3nM- Gastric mucosal

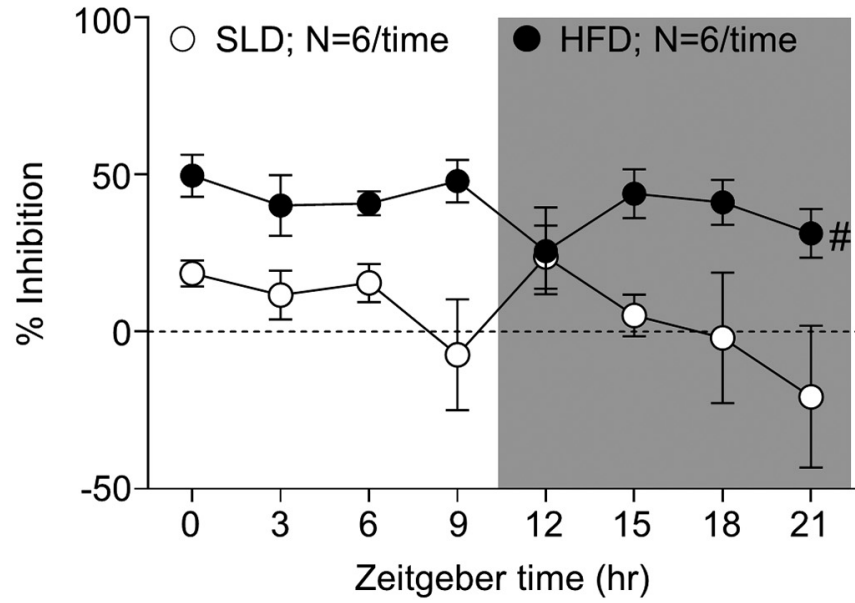

Figure 5. Leptin exhibits a circadian ability to potentiate mucosal GVAs in SLD mice. $A$, Percentage inhibition of baseline mechanosensitivity of tension receptor response to $3 \mathrm{~g}$ tension caused by leptin in SLD and HFD mice. $\boldsymbol{B}$, Percentage potentiation of baseline mechanosensitivity of mucosal receptors to mucosal stroking with a 50 mg von Frey hair induced by leptin in SLD and HFD mice. C, Percentage inhibition of tension receptor response to $3 \mathrm{~g}$ tension caused by ghrelin in SLD and HFD mice. D, Effect of ghrelin on mucosal receptor response to $50 \mathrm{mg}$ von Frey hair in SLD and HFD mice. $\# p<0.05$ versus SLD, two-way ANOVA diet effect.

sponse of SLD gastric mucosal receptors to mucosal stroking and the gastric content (Fig. $4 E ; r=-0.49, p<0.0001$ ). HFD mice exhibited minimal variation in mucosal receptor mechanosensitivity (Fig. $4 D$ ) and there was no relationship between mechanosensitivity and gastric content (Fig. 4F; $r=-0.03, p=0.3995$ ). A two-way ANOVA revealed a significant interaction between the circadian oscillation of gastric mucosal receptor mechanosensitivity between the two diet groups $\left(F_{(7,104)}=3.2, p<0.0041\right.$, two-way ANOVA, diet $X$ time of day interaction).

Effect of leptin on gastric vagal afferent mechanosensitivity Leptin caused inhibition of tension receptors only from HFD mice, as described previously (Kentish et al., 2014). The level of inhibition caused by leptin was relatively static $(\approx 31 \%)$ throughout the circadian cycle in HFD mice (Fig. 5A). No leptin-induced inhibition of tension receptors was observed at any time point in SLD mice (Fig. 5A). A two-way ANOVA revealed that diet $\left(F_{(7,104)}=39.50, p<0.0001\right.$, two-way ANOVA, diet effect), but not time of day ( $p=0.6141$, twoway ANOVA, time of day effect), had a significant impact on the inhibitory effect of leptin on tension receptor mechano- sensitivity. No interaction between diet and time of day was detected by the two-way ANOVA ( $p=0.1842$, two-way ANOVA, diet $\times$ time of day interaction).

Leptin potentiated mucosal receptor mechanosensitivity in SLD mice as described previously (Kentish et al., 2014). Leptin-induced potentiation of SLD mucosal mechanosensitivity varied throughout the circadian cycle with an acrophase level observed at ZT3 $(\approx 69 \%)$, which remained stable throughout the LP, but decreased during the DP, dropping to a trough level $(\approx 10 \%)$ at ZT18 (Fig. $5 B)$. Leptin failed to potentiate the mechanical sensitivity of gastric mucosal receptors from HFD at any time point (Fig. 5B). A two-way ANOVA revealed a significant interaction between the circadian oscillation of leptin-induced potentiation of gastric mucosal receptor mechanosensitivity between the two diet groups $\left(F_{(7,104)}=\right.$ 2.2, $p=0.0422$, two-way ANOVA, diet $\times$ time of day interaction).

Effect of ghrelin on gastric vagal afferent mechanosensitivity Ghrelin caused a static level of inhibition of tension receptor mechanosensitivity from both SLD and HFD mice throughout 

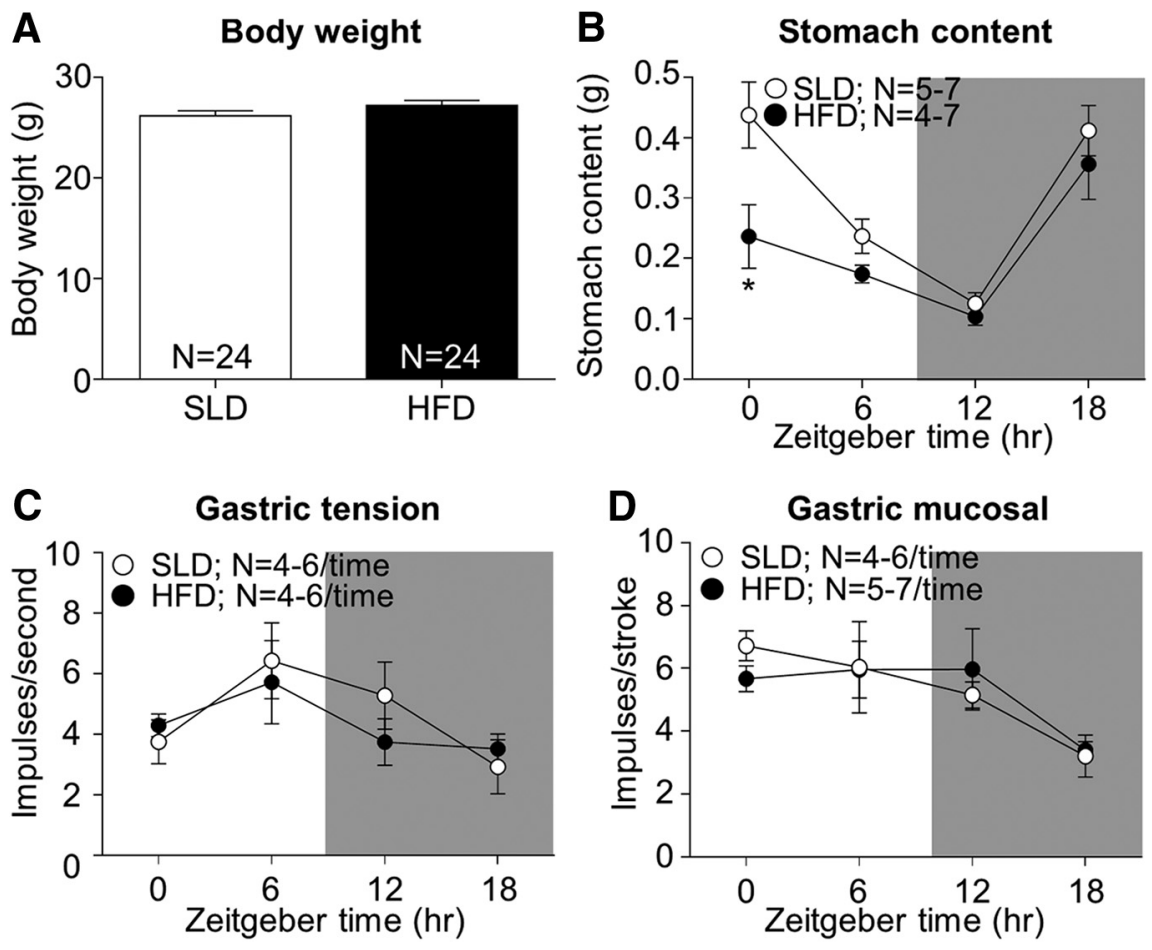

Figure 6. Circadian variation in GVA mechanosensitivity is still present after 2 weeks of HFD feeding. $A$, Body weight of SLD and HFD mice after 2 weeks of diet feeding. $\boldsymbol{B}$, Circadian variation in gastric content of SLD and HFD mice after 2 weeks of diet feeding. $\boldsymbol{C}, \boldsymbol{D}$, Age-matched SLD and HFD gastric tension receptor responses to $3 \mathrm{~g}$ stretch $(\boldsymbol{C})$ and mucosal receptor response to mucosal stroking with a $50 \mathrm{mg}$ von Frey hair throughout the circadian cycle $(\boldsymbol{D}) .{ }^{*} p<0.05$, two-way ANOVA Sidak post hoc test.

the circadian cycle (Fig. 5C). A two-way ANOVA revealed that neither diet ( $p=0.6307$, two-way ANOVA, diet effect) nor time of day ( $p=0.5907$, two-way ANOVA, time of day effect) had a significant impact on the inhibitory effect of ghrelin on tension receptor mechanosensitivity. No interaction between diet and time of day was detected by the two-way ANOVA ( $p=0.5567$, two-way ANOVA, diet $\times$ time of day interaction).

Ghrelin induced a static level of inhibition of mucosal receptor mechanosensitivity in HFD mice, which was not seen at any time point in SLD mice (Fig. 5D). A two-way ANOVA revealed that diet $\left(F_{(7,104)}=36.2, p<0.0001\right.$, two-way ANOVA, diet effect), but not time of day ( $p=0.3586$, two-way ANOVA, time of day effect), had a significant impact on the inhibitory effect of ghrelin on mucosal receptor mechanosensitivity. No interaction between diet and time of day was detected by the two-way ANOVA $(p=0.4145$, two-way ANOVA, diet $\times$ time of day interaction).

Circadian oscillations in gastric afferent mechanosensitivity after 2 weeks on an HFD

After 2 weeks of HFD feeding, there was no difference in mouse weight (SLD $26.16 \pm 0.51 \mathrm{~g}$, HFD $27.22 \pm 0.48 \mathrm{~g}, p=0.1351$, unpaired $t$ test; Fig. $6 A$ ). There was circadian variation in gastric content in both the 2-week HFD and aged-matched SLD mice (Fig. $6 B$ ), with trough values of $0.126 \pm 0.018 \mathrm{~g}$ (SLD) and $0.104 \pm 0.015 \mathrm{~g}$ (HFD) occurring at ZT12 and acrophase levels of $0.412 \pm 0.042 \mathrm{~g}$ (SLD) and $0.356 \pm 0.058 \mathrm{~g}$ (HFD). Two-way ANOVA analysis of the gastric content of the two groups revealed that both time of day $\left(F_{(3,39)}=22.5, p<0.0001\right.$, two-way ANOVA, time of day effect) and diet $\left(F_{(1,39)}=10.5, p=0.0024\right.$, two-way ANOVA, diet effect) significantly affected gastric content. Post hoc analysis revealed that there was significantly less food in the stomachs of the 2-week HFD mice $(0.237 \pm 0.052 \mathrm{~g})$ compared with the SLD mice $(0.437 \pm 0.055 \mathrm{~g})$ at ZT0 $(p<$ 0.01, two-way ANOVA, diet effect, Sidak post hoc test). However, the two-way ANOVA revealed no interaction between the time of day and diet (Fig. $6 B, p=0.14$, two-way ANOVA, diet $x$ time of day interaction).

In mice fed a HFD or SLD for 2 weeks, there was significant circadian variation in tension receptor mechanosensitivity (Fig. $6 C, F_{(3,35)}=3.0, p=0.043$, two-way ANOVA time-of-day effect). The twoway ANOVA revealed that diet $(p=$ 0.6973, two-way ANOVA, diet effect) had no significant impact on tension receptor mechanosensitivity and there was no interaction between diet and time of day detected by the two-way ANOVA ( $p=$ 0.6436, two-way ANOVA, diet $\times$ time of day interaction). Similarly, mucosal receptor mechanosensitivity in both the SLD and HFD mice varied throughout the circadian cycle (Fig. $6 D, F_{(3,34)}=4.5, p=$ 0.0089 , two-way ANOVA time of day effect), with no significant difference caused by diet ( $p=0.9618$ two-way ANOVA, diet effect). There was no significant interaction revealed by the two-way ANOVA between time of day and diet in regard to mucosal receptor mechanosensitivity $(p=0.7621$ two-way ANOVA, diet $\times$ time of day interaction). Together, this indicates that the exposure to an HFD for 2 weeks was not sufficient to cause the ablation in GVA circadian rhythmicity.

\section{Discussion}

We demonstrate that HFD-induced obesity in mice abrogates the circadian variation in GVA mechanosensitivity. This was associated with an increase in eating behavior during the LP, but not with any detectable changes in clock gene expression in the nodose ganglia.

We confirm our previous findings on the circadian expression of clock genes in the nodose ganglia. In addition to Per1, Per2, Bmal1, and Nr1d1, we now demonstrate circadian expression of the clock genes Cry1, Cry2, and Clock in the nodose ganglia. Unlike previous studies examining clock gene expression in the fat and liver (Kohsaka et al., 2007), all of the clock genes that we studied continue to exhibit circadian oscillations in HFD mice of the same timing and magnitude. Given that there were no detectable changes in circadian clock gene expression between the SLD and HFD mice in the whole nodose ganglia makes the mechanism responsible for the change in the circadian pattern of GVA mechanosensitivity unclear. It should be noted that there was noticeable variation between samples, which, due to the small sample size, made it difficult to fit an accurate circadian pattern. In addition, it is important to note that the changes in mechanosensitivity occurs in a specific subpopulations of vagal afferents that account for a small percentage of the neurons within the nodose ganglia (Kentish et al., 2013), whereas the qRT-PCR experiments are based on whole nodose ganglia. Isolating specific GVA cell bodies may reveal changes in clock gene rhythmicity in HFD mice because we previously identified changes in leptin 
receptor expression in gastric afferents that were not observable in the whole nodose ganglia (Kentish et al., 2014). The prospect of using laser capture microdissection to perform the necessary isolation is one that warrants future study. However, the surgery for the gastric retrograde tracing requires a period of recovery during which normal food intake is disturbed, likely altering clock gene expression because peripheral clock gene expression has been shown to be entrainable by food intake (Schibler et al., 2003). Therefore, future studies will be needed to verify the best and most appropriate method of tracing and then collecting specific subpopulations of nodose neurons for the purpose of analyzing circadian rhythms.

Lean rodents consume fewer and smaller meals during their LP (Ho and Chin, 1988; Treesukosol and Moran, 2014). Our previous findings, confirmed in this report, suggest that increased sensitivity of GVAs during the LP may provide a mechanism for this reduction. In particular, the increase in tension receptor mechanosensitivity may lead to increased ascending satiety signaling in response to a smaller meal during the LP to restrict food intake. Conversely, the reduced response to stretch observed during the DP would allow a greater amount of food to be accommodated in the stomach before a sufficient signal is initiated to terminate food intake. This is consistent with our metabolic data indicating that lean mice consume larger meals during the DP compared with the LP.

Previous reports have shown that HFD rats exhibit increased LP meal size without a change to meal number, $24 \mathrm{~h}$ energy intake, or DP food intake (Furnes et al., 2009). Our results in HFD mice similarly show an increased meal size during the LP. However, $24 \mathrm{~h}$ energy consumption and meal number were also increased during the LP, representing potential differences between HFD rats and mice. The increased meal size during the LP in the HFD mice suggests that there may be an impaired ability to sense the fullness of the stomach in response to eating. Consistent with this, there was no increase in mechanosensitivity of tensionsensitive GVAs (relative to DP) during the LP in HFD mice, which may represent a dysfunction that is permissive of the consumption of larger meals during the day. This static mechanosensitivity may explain why the HFD mice did not consume larger meals during the DP, instead consuming smaller meals. The $\approx 9 \%$ reduction in meal size during the DP in HFD mice is interesting, but requires further investigation to elucidate the significance.

Mucosal afferents are thought to be involved in the discrimination of particle size to delay gastric emptying (Becker and Kelly, 1983). Although we are unable to comment explicitly on the correlation between variations in mucosal receptor mechanosensitivity and rate of gastric emptying, previous studies have established that gastric emptying does vary throughout the circadian cycle, with slower gastric emptying during times of reduced habitual eating (Vachon and Savoie, 1987). This is consistent with our observed increase in mucosal receptor mechanosensitivity during the LP, when lean mice consume less food.

HFD-induced obesity has been reported to cause changes in the rate of gastric emptying. The reports are inconsistent with reports of no difference (Buchholz et al., 2013), increased (Baudry et al., 2012), and decreased rates of gastric emptying (Kentish et al., 2015). There are no studies that have addressed whether the circadian pattern of gastric emptying is altered in obesity. Furthermore, it remains to be investigated whether there is any link between the change in mucosal GVA mechanosensitivity and the disruption to the normal pattern of gastric empty- ing. On the basis of our findings, we would speculate that circadian variation in gastric emptying should be reduced in HFD mice, but this requires further investigation.

Modulation of satiety signaling by peptide mediators forms an important part of the regulation of food intake (Kentish and Page, 2014). We have shown previously that ghrelin and leptin can modulate GVA activity (Kentish et al., 2012; Kentish et al., 2014). In addition, it has been established that leptin can depolarize vagal neurons directly (Peters et al., 2006) and that the ability for leptin to act on upper gastrointestinal vagal afferents is important in the regulation of food intake (Peters et al., 2005). It has also been demonstrated that vagal leptin signaling is disrupted in diet-induced obesity and results in hyperphagia and weight gain (de Lartigue et al., 2011, 2014). We now provide evidence that the ability of leptin to potentiate mucosal GVA mechanosensitivity (potentially contributing to the regulation of food intake) in SLD mice is reduced during the DP. This reduction may allow for increased food to be consumed during the DP, when energy demand is usually higher. Alternatively, it may be involved in the circadian oscillation in gastric emptying (Cakir et al., 2007). The mechanism that drives the change in the ability for leptin to modulate mucosal GVA mechanosensitivity is still to be determined.

The observation that circadian fluctuations in the mechanosensitivity of GVAs from mice that have only been fed a HFD for 2 weeks suggests that the ablation in GVA mechanosensitivity in the HFD obese mice is likely caused by a change that comes about as a result of the increased weight of the mice rather than being a direct effect of the diet. Alternatively, we cannot rule out that 2 weeks on the HFD is just not sufficiently long enough to cause the changes. However, it has been shown previously that vagal sensitivity to leptin and cholecystokinin is ablated in HFD-fed obese Sprague Dawley rats, but not diet-matched obesity-resistant rats (de Lartigue et al., 2011, 2012; Duca et al., 2013). In contrast, others have shown that short periods of HFD feeding (before the onset of obesity) is sufficient to decrease the ability for glucose to amplify vagal responses to 5-HT and CCK to increase vagal activity (Troy et al., 2016). Therefore, although it is likely that the ablation in GVA circadian rhythm is due to the development of obesity, further experiments are required to absolutely rule out the impact of the diet itself.

In conclusion, circadian variation in GVA mechanosensitivity in HFD-induced obese mice is completely lost and this is accompanied by changes in food intake behavior that are independent of clock gene expression patterns. This demonstrates that the peripheral vagal afferent rhythms are susceptible to disturbances caused by the obese state itself. However, crucially, the mechanism responsible for this disturbance still needs to be determined and a direct causal link between the variation in meal size and oscillation in GVA mechanosensitivity still needs to be established.

\section{References}

Baudry C, Reichardt F, Marchix J, Bado A, Schemann M, des Varannes SB, Neunlist M, Moriez R (2012) Diet-induced obesity has neuroprotective effects in murine gastric enteric nervous system: involvement of leptin and glial cell line-derived neurotrophic factor. J Physiol 590:533-544. CrossRef Medline

Becker JM, Kelly KA (1983) Antral control of canine gastric emptying of solids. Am J Physiol 245:G334-G338. Medline

Buchholz V, Berkenstadt H, Goitein D, Dickman R, Bernstine H, Rubin M (2013) Gastric emptying is not prolonged in obese patients. Surg Obes Relat Dis 9:714-717. CrossRef Medline

Cakir B, Kasimay O, Devseren E, Yeğen BC (2007) Leptin inhibits gastric emptying in rats: role of CCK receptors and vagal afferent fibers. Physiol Res 56:315-322. Medline 
Cummings DE, Overduin J (2007) Gastrointestinal regulation of food intake. J Clin Invest 117:13-23. CrossRef Medline

de Lartigue G, Barbier de la Serre C, Espero E, Lee J, Raybould HE (2011) Diet-induced obesity leads to the development of leptin resistance in vagal afferent neurons. Am J Physiol Endocrinol Metab 301:E187-E195. CrossRef Medline

de Lartigue G, Barbier de la Serre C, Espero E, Lee J, Raybould HE (2012) Leptin resistance in vagal afferent neurons inhibits cholecystokinin signaling and satiation in diet induced obese rats. PLoS One 7:e32967. CrossRef Medline

de Lartigue G, Ronveaux CC, Raybould HE (2014) Deletion of leptin signaling in vagal afferent neurons results in hyperphagia and obesity. Mol Metab 3:595-607. CrossRef Medline

Denis RG, Williams G, Vernon RG (2003) Regulation of serum leptin and its role in the hyperphagia of lactation in the rat. J Endocrinol 176: 193-203. CrossRef Medline

Duca FA, Zhong L, Covasa M (2013) Reduced CCK signaling in obeseprone rats fed a high-fat diet. Horm Behav 64:812-817. CrossRef Medline

Furnes MW, Zhao CM, Chen D (2009) Development of obesity is associated with increased calories per meal rather than per day: a study of high-fat diet-induced obesity in young rats. Obes Surg 19:1430-1438. CrossRef Medline

Gillette MU, Tischkau SA (1999) Suprachiasmatic nucleus: the brain's circadian clock. Recent Prog Horm Res 54:33-58; discussion 58-59. Medline

Ho A, Chin A (1988) Circadian feeding and drinking patterns of genetically obese mice fed solid chow diet. Physiol Behav 43:651-656. CrossRef Medline

Kentish SJ, Page AJ (2014) Plasticity of gastro-intestinal vagal afferent endings. Physiol Behav 136:170-178. CrossRef Medline

Kentish S, Li H, Philp LK, O’Donnell TA, Isaacs NJ, Young RL, Wittert GA, Blackshaw LA, Page AJ (2012) Diet-induced adaptation of vagal afferent function. J Physiol 590:209-221. CrossRef Medline

Kentish SJ, Frisby CL, Kennaway DJ, Wittert GA, Page AJ (2013) Circadian variation in gastric vagal afferent mechanosensitivity. J Neurosci 33: 19238-19242. CrossRef Medline

Kentish SJ, O’Donnell TA, Frisby CL, Li H, Wittert GA, Page AJ (2014) Altered gastric vagal mechanosensitivity in diet-induced obesity persists on return to normal chow and is accompanied by increased food intake. Int J Obes (Lond) 38:636-642. CrossRef Medline

Kentish SJ, Ratcliff K, Li H, Wittert GA, Page AJ (2015) High-fat diet induced changes in gastric vagal afferent response to adiponectin. Physiol Behav 152:354-362 CrossRef Medline

Kohsaka A, Laposky AD, Ramsey KM, Estrada C, Joshu C, Kobayashi Y, Turek FW, Bass J (2007) High-fat diet disrupts behavioral and molecular circadian rhythms in mice. Cell Metab 6:414-421. CrossRef Medline

Page AJ, Martin CM, Blackshaw LA (2002) Vagal mechanoreceptors and chemoreceptors in mouse stomach and esophagus. J Neurophysiol 87: 2095-2103. Medline

Pendergast JS, Branecky KL, Yang W, Ellacott KL, Niswender KD, Yamazaki S (2013) High-fat diet acutely affects circadian organisation and eating behavior. Eur J Neurosci 37:1350-1356. CrossRef Medline

Peters JH, McKay BM, Simasko SM, Ritter RC (2005) Leptin-induced satiation mediated by abdominal vagal afferents. Am J Physiol Regul Integr Comp Physiol 288:R879-R884. Medline

Peters JH, Ritter RC, Simasko SM (2006) Leptin and CCK modulate complementary background conductances to depolarize cultured nodose neurons. Am J Physiol Cell Physiol 290:C427-C432. Medline

Pfaffl MW, Horgan GW, Dempfle L (2002) Relative expression software tool (REST) for group-wise comparison and statistical analysis of relative expression results in real-time PCR. Nucleic Acids Res 30:e36. CrossRef Medline

Schibler U, Ripperger J, Brown SA (2003) Peripheral circadian oscillators in mammals: time and food. J Biol Rhythms 18:250-260. CrossRef Medline

Treesukosol Y, Moran TH (2014) Analyses of meal patterns across dietary shifts. Appetite 75:21-29. CrossRef Medline

Troy AE, Simmonds SS, Stocker SD, Browning KN (2016) High-fat diet attenuates glucose-dependent facilitation of 5-HT mediated responses in rat gastric vagal afferents. J Physiol 594:99-114. Medline

Vachon C, Savoie L (1987) Circadian variation of food intake and digestive tract contents in the rat. Physiol Behav 39:629-632. CrossRef Medline

Wang GJ, Tomasi D, Backus W, Wang R, Telang F, Geliebter A, Korner J, Bauman A, Fowler JS, Thanos PK, Volkow ND (2008) Gastric distention activates satiety circuitry in the human brain. Neuroimage 39:1824-1831. CrossRef Medline 